\title{
As interpretações do ius fetiale e a inaplicabilidade de conceitos modernos à cultura romana antiga
}

\author{
Luciene Dal Ri ${ }^{1}$
}

Resumo: O artigo é de cunho historiográfico e analisa as interpretações da doutrina sobre o complexo de normas que constituem o ius fetiale a partir do século XIX, evidenciando as diferentes concepções modernas da relação entre direito e religião na Antiguidade. Como conseqüência dessas teorias, o ius fetiale foi e frequentemente ainda é tratado como estritamente religioso, não sendo reconhecido como direito, como "direito internacional", como "direito público externo", ou como "direito supranacional". Observam-se, nessas linhas, de um lado a pressuposição do conceito de "Estado" e a mutilação da realidade histórica, e de outro a compreensão do universalismo romano nas especificidades da sua cultura.

Palavras-chave: Ius fetiale. Direito. Religião. Direito internacional. Direito público externo.

\begin{abstract}
This article is a stamp and analyzes the historiographical interpretations of the doctrine on the set of rules that constitute the ius fetiale from the nineteenth century, highlighting the different conceptions of the modern relationship between law and religion in Antiquity. As a consequence of the theories, ius fetiale was and is still often treated as strictly religious, not being recognized as a right, as "international law", as "foreign public law", or "supranational law." It is observed in these lines from one side to the assumption of the concept of "state" and the mutilation of historical reality, and from the other, the understanding of the Roman universalism, the specificities of their culture.
\end{abstract}

Keywords: Ius fetiale. Law. Religion. International law. Foreign public law.

\section{Introdução: a importância do ius fetiale}

O estudo do ius fetiale, como conjunto de normas, pode ser considerado um dos principais aspectos para a compreensão das relações

1 Doutora em Direito Civil-romanístico pela Università degli Studi di Roma "La Sapienza" (2009). Mestre em Direito Romano pela Università degli Studi di Roma "La Sapienza" (2004) e em Estudos Medievais pela Pontificia Università Antonianum, Roma (2006). Professora nos cursos de graduação e mestrado da Universidade Regional do Noroeste do Rio Grande do Sul e pesquisadora da Fondazione Cassamarca, Itália. E-mail: luciene.dalri@unijui.edu.br. 
da Roma antiga com outros povos e reis. A importância da atividade externa romana regida pelo ius fetiale durante o período régio (753-509 a.C.) e aquele republicano (509-27 a.C.) ganha particular importância com a expansão romana dentro da comunidade latina e posteriormente itálica, sendo sempre ponto de referência normativo na formação do imperium dos romanos.

A importância desse complexo de institutos enseja a constatação de que algumas das suas noções típicas apresentam posterior continuidade no tempo através de normas presentes nos iura communia/direitos comuns e nos iura gentium/direitos das gentes (CATALANO, 1990, p. 42). ${ }^{2} \mathrm{O}$ estudo e a "aplicação" do ius fetiale não se limitou à Antiguidade e foi visto durante os períodos medieval e moderno como um ponto de referência e até mesmo como fonte do direito, apesar da variada dinâmica aplicada no tempo, através da qual guiar as "relações externas" de diferentes tipos de comunidades, abarcando até mesmo a problemática relativa à legitimidade teológica e jurídica das "relações externas" do império e da cristandade (ILARI, 1981, p. 21). Essa concepção começa a mudar a partir do período moderno quando se observa a tendência em conceber o direito romano como um exemplum historicum, mais através de uma óptica liberal e individualista do que como uma verdadeira fonte do direito (ILARI, 1981, p. 50; BRUSCHI, 2004, p. 27).

As notícias que se têm sobre os feciais são provenientes de epígrafes, obras de antiquários, juristas e historiadores gregos e latinos. Essas fontes, primárias e secundárias, são provenientes em sua maior parte do período clássico (II a.C.-II d.C.) e pós-clássico (II-IV d.C.), muitas vezes posteriores em séculos aos fatos relatados. Parte-se do pressuposto de que aquelas sejam confeccionadas com base nos documentos sacerdotais, nas obras especializadas e no conhecimento comum dos cidadãos romanos sobre o tema.

A literatura latina torna-se fonte primordial por transmitir fórmulas e rituais realizados pelos sacerdotes feciais na regulamentação de

2 Neste sentido, é particularmente interessante ter presente, como evidencia Catalano (1960, p. 593), “[...] l'importanza che per la formazione della tradizione ebbero $i$ documenti sacerdotali (in particolare i libri e i commentarii)". 
determinadas relações jurídicas, como a realização de "tratados" e o procedimento para a declaração de guerra. ${ }^{3}$

A preocupação da doutrina com a tradição e a disciplina dos sacerdotes feciais não é recente, mas plenamente constatada no final do século XVI através do pensamento de Alberico Gentili, ${ }^{4}$ considerando o escasso tratamento do direito de guerra no direito justinianeu via ius fetiale uma possibilidade de referência normativa. $\mathrm{O}$ autor afirma, porém, a impossibilidade de conhecimento das normas e institutos relativos a esse ius, devido à perda dos seus livros. ${ }^{5}$ Mais de cinqüenta anos depois, Richard Zouche (ZOUCHE, 1911, p. 2), ${ }^{6}$ sucessor de Gentili, contrapõe-

3 Algumas fontes latinas que atestam a importância e atividade dos feciais: Varro, ling. Lat. 5,86; Varro, pop. Rom. 2,75; Cícero rep. 2,17,31; Cícero off. 1,11,36; Tito Lívio 1,24,4-10; 1,32,5-14; Paulo Diácono, Fest. ep. p. 81; Aulo Gelio 16,4,1; Nonio Marcelo 12 p. 617 Q; Servio 9,52 e 10,14. Têm-se também algumas fontes gregas que atestam a importância e a atividade dos feciais: Dionisio de Halicarnasso 2,72; Plutarco, Numa 12,4; Polibio, Hist. 3,25,6-9; Dione Cassio 71,33,3.

4 Alberico Gentili nasceu em São Ginésio no ano de 1552 e morreu em Londres no ano de 1608. "Utique libri, qui fuerant de jure faeciali, bellica haec iura exposita, et constituta habuerunt. Videlicet erant faeciales foederum, pacis, bellorum, legationum, et reliquorum hujus juris cum exteris curatores. Verum nihil nunc ad nos, nisi desiderium operum eorum pervenit. Ut enim sperni coepta est pars ista juris usque a fine reipublicae Romanae, idest, a tempore quo Romani res gerere cum ratione desierunt, pro libidine agere omnia inceperunt, ita librique juris faecialis interiere, et memoriae, et doctores esse desiere. Abit quod non tenetur: et non tenetur, quod in pretio non est” (GENTILI, 1770, p. 3). Sobre o tema, ver Ilari (1981, p. 71). A preocupação de Gentili com o ius fetiale é fruto da importância que a cultura política humanística e o direito romano, além da praxe seguida pelos Estados da época, têm no pensamento do autor. Recordo que as obras de Gentili tiveram uma importante influência sobre os pensadores sucessivos do século XVII, e em particular sobre Ugo Grócio. Ver Panizza (1988, p. 41, 52).

5 É conhecida a dificuldade do jurista em equiparar o conceito de ius ao conceito hodierno de direito. O ius tem um forte caráter religioso e universalístico, sendo vivido e aplicado num particular contexto histórico e geográfico de expansão, em que a validade e a efetividade muitas vezes separam-se, sem comprometer a essência do ius.

6 Richard Zouche nasceu em Ansty, Wiltshire, no ano de 1590 e morreu em Londres no ano de 1661. Dentre as fontes indicadas pelo autor, encontramos notícias estritamente ligadas ao ius fetiale apenas na literatura latina e grega. Poucas são as fontes gregas que trazem referências às atividades que envolviam os sacerdotes feciais, dentre essas, particularmente importantes, estão os relatos de Polibio, Plutarco e Dionísio de Halicarnasso. Sobre o assunto, ver Sini (2005). 
se àquele, afirmando que, mesmo com essa perda, podem-se encontrar notícias relativas ao ius fetiale nos "Livros Sacros", nas Pandetas, no "Codex Juris Romani" e nos escritores gregos e latinos, nos quais opiniões e testemunhos estabelecem o que foi entendido de acordo com a naturalis ratio nos costumes "internacionais".

A impossibilidade de consulta dos documentos do colégio dos feciais, constatada por Gentili (GENTILI, 1770, p. 3; PANIZZA, 1988, p. 41, 52), leva à coleta de material que tenha informações sobre o ius fetiale para conhecer as suas normas, como sugeriu Zouche (ZOUCHE, 1911, p. 2). A doutrina segue em grande parte essa tendência, baseando seus trabalhos nos relatos, particularmente da literatura latina. Uma séria crítica das fontes faz-se sentir, porém, somente a partir do final do século XVIII, ${ }^{7}$ fato que, somado à dificuldade de coleta do material relativo a um período anterior ao século XIX, permite delimitar a pesquisa bibliográfica aos últimos dois séculos.

Essa delimitação temporal exclui, dentre outros, o problema de legitimidade teológica e jurídica das relações externas do império e da cristandade, assim como a influência do direito romano, através do ius fetiale, na regulação do direito internacional durante a idade média e a moderna.

Dentro do período aqui tratado, o estudo do ius fetiale, como parte do direito romano mais antigo, encontra forte impulso apenas na segunda metade do século XX, devido à concepção da importância da religião na formação daquele direito. A relação entre o direito e a religião, no que diz respeito ao ius fetiale, é interpretada e debatida pela doutrina através de diferentes correntes, que muitas vezes refletem (ou impõem) concepções posteriores àquela realidade.

No século XIX, a interpretação das passagens latinas relativas ao ius fetiale é realizada principalmente através da concepção formal-

\footnotetext{
7 Sobre a problemática relativa à análise da doutrina anterior ao século XIX, ver Sini (1983, p. 45). Sobre a importância da anterior crítica das fontes, ver Barbagallo (1926, p. 3): "Fin dal quattrocento eruditi italiani e stranieri, il Valla, il Loriti, il Cluverio, il Gronovio, sopra tutti l'olandese Perizonio nelle sue Animadversiones historicae (Amsterdam, 1865) [...] avevano discusso parecchi punti delle narrazioni di Livio e di altri antichi, e avevano sospettato della loro veridicità e della loro coerenza. Poi il sec. XVIII approfondì, completò, sistematizzò, quei dubbi critici”.
} 
religiosa ou da concepção jurídica, evidenciando a influência positivista e a separação entre religião e juridicidade. Como conseqüência da desvalorização do aspecto jurídico, parte da doutrina apresenta o ius fetiale como um "direito público externo". Contrariamente a essa concepção, alguns autores desvalorizam o aspecto religioso e evidenciam a juridicidade do complexo de normas, apresentando-o como um "direito internacional”. Surge, porém, o problema relativo à aplicação de conceitos modernos ao mundo antigo, gerando uma mutilação da realidade histórica e a conseqüente interpretação parcial do ius fetiale. ${ }^{8}$

O debate de qualificação do ius fetiale, como "direito público externo" ou como "direito internacional", com as suas implicações e conseqüências, não se limita ao século XIX e estende-se até os dias atuais. ${ }^{9}$ Durante o século XX, são evidenciados, porém, ulteriores aspectos da relação entre religião e juridicidade, tratando principalmente da secularização de um direito de origem religiosa, ${ }^{10}$ assim como atribuindo ao ius fetiale, além de aspectos religiosos e jurídicos, também aspectos mágicos.

\section{Uma interpretação estritamente religiosa do ius fetiale}

A interpretação religiosa do ius fetiale é diretamente ligada à concepção que a corrente positivista tem do direito na Antiguidade. O positivismo concebe a ciência jurídica como ciência baseada somente nos juízos de fato, e não nos de valor junto à comunidade; nesse sentido a validade do direito é proporcionada pela coerção estatal. ${ }^{11}$ Essa corrente

8 Sobre os problemas derivados das diferentes concepções do ius fetiale, ver Catalano (1990, p. 32)

9 Confira em Direito Público Externo: De Täuber (1930, p. 295, 311, 325); Wegner (1936, p. 17 e 46); Giuliano (1954, p. 109); Gandolfi (1954, p. 36); Cimma (2000). Em Direito Internacional: Furlani (1945, p. 220). Furlani (1956, p. 290). Paradisi (1947, p. 3360; Bellini (1958, p. 3; 39; 73); Bellini (1962, p. 511).

${ }^{10}$ Sobre a historiografia romanística, ver: De Ruggiero (1875); Orestano (1963); Crifò (1998).

${ }^{11}$ Um bom exemplo dessa linha de pensamento está em Laurent (1850, p. 21) ao afirmar que o caráter religioso da indictio belli, expresso através de suas fórmulas e ritos, tem escasso valor para moderar o abuso da força, negando os limites do vencedor no confronto 
sustenta a teoria de Vico ${ }^{12}$ de hostilidade natural e de ausência de relações internacionais entre os povos da Antiguidade - fora daquelas fundadas sobre a comunidade racial ou os seus tratados ${ }^{13}$ - assim como atribui conceitos modernos à realidade antiga, impondo conseqüentemente a separação entre direito e religião e limitando o ius fetiale à esfera religiosa. ${ }^{14}$

Tendo como influxo o evolucionista, essa corrente tende, porém, a atenuar a separação entre direito e religião durante o período arcaico. Tal fato reflete-se na concepção da atividade dos feciais em período mais antigo, reconhecendo a esses sacerdotes o papel de magistrados, que conduziam negociações entre o povo romano e um "Estado" estrangeiro. ${ }^{15}$

do vencido, mesmo se as condições de exercício do direito do vencedor fossem definidas e limitadas pelas normas de declaração de guerra, tréguas e festas religiosas.

12 Vico (1744, libro II, sezione V, cap. VI). Ver também do mesmo autor (1721, caput XXX) De constantia iurisprudentis: "Tal nimicizia eterna tralle prime città non richiedeva che fussero le guerre intimate, e sì tali ladronecci si riputarono giusti; come, per lo contrario, disavezzate poi di barbaro costume sì fatto le nazioni, avvenne che le guerre non intimate son ladronecci, non conosciuti ora dal Diritto natural delle genti che da Ulpiano son dette umane".

${ }^{13}$ Como um dos extremistas dessa tese, Täubler (1964, p. 402): "Auf den primitivisten Kulturstufen wird man an Tötung aus Angst, Menschenfrass und Menschenopfer denken, als erste Entwicklungsstufe die Wehrwahndung des Fremden als Sklave annehmen müssen. Hier trennt sich dann die Entwicklung des Staatenvertrags und Gastvertrags. Der Unterschied darf nicht darin gesucht werden, dass die Entwicklung des einen vom Staate ausgehen muss, die des anderen von jeden einzelnen ausgehen kann, beruht vielmehr darauf, dass die Entwicklung, die zum Staatsvertrag führt, den Gefangenen zum Geisel macht, ihn für die Gemeinschaft, welcher er angehört, bürgen lässt, die zum Gastvertrage führende dagegen den Fremden nicht in Beziehung zu einem dritten setzt und deshalb nicht zu dessen Bürgen umwandelt vielmehr den Sklaven zum freien Mann und den freien Mann vertragsmässing als Eigenbürgen zum Gastfreund macht".

${ }_{14}$ Sobre "Estado", direito e religião romana, ver Hegel (1963, p. 178). Sobre Hegel e positivismo jurídico no direito romano, ver Catalano (1996, p. 146). Seguindo o influxo hegeliano, Mommsen, ao introduzir o conceito abstrato de "Estado" o identifica com o de povo. Sobre a concepção hegeliana de Mommsen, ver Catalano (1974, p. 44).

${ }^{15}$ Mommsen (1887, p. 676). Até mesmo Schulz identifica os mais antigos juristas romanos como sacerdotes, "jurist of sacral law", "priests and magistrates at one and the same time" (SCHULZ, 1953, p. 6). 
A corrente positivista precede a obra de Mommsen e é presente nos trabalhos de Rein (1844, p. 466), ${ }^{16}$ em 1844, Laurent (1850, p. 12), ${ }^{17}$ Voigt $^{18}$ em 1852 e Ramsay (1875), que afirmam, por exemplo, a natureza formal e religiosa do ius fetiale. Essa concepção influencia fortemente a doutrina da época ${ }^{19}$ não apenas nos estudos de cunho jurídico, mas também naqueles de cunho religioso (MOMMSEN, 1943, p. 119). ${ }^{20}$

${ }^{16} \mathrm{O}$ autor atribui aos feciais as seguintes funções: "1) verhandlungen und Erklärungen vor dem Krieg; 2) Friendenschluss nach Beendigung des Kriegs; 3) Sorge für die Erhaltung des geschlossen Vertrags".

17 "Les romains étaient un peuple très-religieux, aux moins dans l'observation des cérémonies prescrites par le culte. Ils n'entreprenaient rien, ni dans la guerre, ni dans la paix, sans avoir au préalable consulté les augures". Assim, o ius fetiale apresenta-se como um conjunto de fórmulas e de regras a serem observadas para declarar a guerra e realizar a paz. “ C'est le sénat et le peuple qui décident la guerre sans consulter le collége des feciaux; ceuxci n'apparaissent que pour présider à l'observation des cérémonies religieuses" (ibidem, p. 14). Inicialmente, os feciais eram os juízes da legitimidade das guerras; posteriormente, a intervenção deles foi relativa apenas a certas solenidades, denotando guerra justa quando as cerimônias religiosas foram corretamente realizadas pelos feciais.

18 Assim, Voigt - mesmo afirmando que os "Fetiales sunt institutum juris gentium Italicarum" - especifica que os princípios e a matéria de direito cabem ao ius gentium, enquanto o rito e as cerimônias, assim como as generalidades das formas relativas às relações cabem aos fetiales (VOIGT, 1852, p. 8, 12). "Fetiales sunt sacerdotes et solummodo sacra illa forma induta negotia exsequuntur, quamobrem, hac forma, itaque religionis ratione, deficiente, nunquam agebant fetiales" (VOIGT, 1852, p. 55). “Arbitria a fetialibus dicta, quae vocantur decreta, ad solas externas actuum ab ipsis perficiendorum formas spectasse, non solum ex exemplis nobis traditis, sed etiam ex universo illorum munere intelligitur". Sobre ius gentium como Völkrrecht, ver Voigt (1858, p. 8, 24). Voigt afirma sobre o tema. Ver Catalano (1990, p. 32).

19 Samter (1909) define o colégio dos feciais como "römisches Priesterkollegium", que se ocupa de sakralen Formen: "Auf Befragen des Senats oder des Magistrats hat das Kollegium der F. Gutachten über die zu beobachtenden völkerrechtlichen Formen zu erteilen, so über die Form der Kriegserkärung (liv. XXXI,8,3; XXXVI,3,7) oder die Auslieferung eines Schuldigen (nach Varro bei Non. p. 529,21 könnte es scheinen, als ob den F. selbst eine Art Gerichtsbarkeit, ein Strafrecht über diejenigen, die Gesandte verletzt haben, zustände, nach Plut. Numa 12; Camill. 18 erteilen die F. nur dem Senat den Rat, den Schuldigen" [Fabius Ambustus, der für die Clusiner gegen die Gallier gekämpft hat] auszuliefern, vgl. Auch Val. Max. VI 6.3).

20 A sobreposição entre jurídico e religioso se manifesta para Mommsen no período real onde o rei une em si sacerdócio e magistratura em uma sobreposição de cargos que pode refletir ao máximo uma sobreposição de aspectos. Tal fato não teria sido continuado na República.. No mesmo sentido, Marquardt (1890, p. 143). 
Mommsen (1887, p. 235), ${ }^{21}$ aplicando essas teorias às relações entre os povos, limita a realização dos tratados a uma troca de perguntas e respostas. Neste sentido, o ritual realizado pelos sacerdotes feciais, em função de um tratado (foedera) (MOMMSEN, 1887, p. 248), ${ }^{22}$ não é o ritual de realização dos tratados, mas um aspecto religioso realizado posteriormente àquele e que buscava reforçar uma obrigação que não podia ser perseguida judicialmente (MOMMSEN, 1887, p. 251). ${ }^{23}$

Os foedera apresentam-se, então, como uma comunhão em que os povos-partes conhecem e reconhecem uma relação religiosa e suas implicações, aceitando a jurisdição divina. ${ }^{24}$ Como conseqüência dessa ligação religiosa tem-se uma relação de amizade, superando a inimizade natural presente nas sociedades primitivas. A relação pacífica entre dois povos, baseada em um foedus demonstra-se relevante também em aspecto bélico, no qual, somente com a ruptura daquele, a guerra pode ser justa.

21 "Die scharfe juristische Auffassung der Römer hat dies nicht bloss anerkannt, sondern auch, wie im Privatrecht, die praktische Abhülfe für die mangelnde bindende Kraft auf dem religiösen Gebiete gefunden. Wie in dem älteren Privatrecht der Eid gebraucht wird, um eine nicht rechtlich verfolgbare Verpflichtung zu stützen, so wird im öffentlichen Recht die Gemeindeverpflichtung, wo ihr die Unwiderruflichkeit gegeben werden soll, von den rechten Vertretern der Gemeinde kraft ihrer amtlichen Befugniss oder nach besonders ertheilter Vollmacht ,geheiligt‘ (sanctum) oder, nach der später üblichen Verstärkung, ,durch Eidschwur geheiligt' (sacro sanctum) " (Cf. Ibidem, p. 249).

22 Mommsen salienta a inicial forma dos tratados como sponsio que logo perdeu seu caráter religioso e passou a ser reforçada pela realização do ritual do foedus, que implica um sermão recíproco. Para o autor, a origem dos tratados internacionais encontra-se no hospitium publicum, do qual os outros seriam variantes. Da mesma opinião, Taddei (1887, p. 98-101). Sob influência Mommseniana, embora com modificações, Brassloff (1928). Täubler (1964, p. 397) sobre a origem dos tratados romanos, afirma a deditio, enquanto tratado de submissão, como o mais antigo. Heuss (1933, p. 33) contrapõe-se a essa concepção pelo fato de a deditio não ser um verdadeiro tratado.

${ }^{23}$ Os foedera têm como característica o sermão de juramento que empenha diretamente o povo, e em decorrência desse santifica e torna inviolável o tratado. A participação dos feciais para a sua realização não é obrigatória, mas garante a regularidade da conclusão e a observação do tratado, assim como o reconhecimento público do mesmo.

${ }^{24} \mathrm{O}$ autor define a guerra justa como "guerra regular" (Römische Staatsrecht I, p. 134). A concepção formal-religiosa de Mommsen sobre o ius fetiale influencia parte da doutrina (LE FUR, 1939, p. 24; REDSLOB, 1923, p. 52; VAN KAN, 1938, p. 388; ALBERT, 1980, p. 12). 
A natureza religiosa do ius fetiale e a sua conseqüente limitação em âmbito jurídico impedem a doutrina romanista de cunho positivista de identificá-lo com o conceito moderno de "direito internacional", visto que esse último tem características estritamente jurídicas (MOMMSEN, 1887 , p. 343). ${ }^{25}$

\section{A coexistência do direito e da religião}

Durante os séculos XVIII e XIX, em paralelo à corrente positivista, desenvolve-se na doutrina uma diversa concepção de ius, e conseqüentemente de ius fetiale, na qual o caráter divino ou sacro não exclui aquele jurídico (CONRADI, 1734, p. 45, 108). ${ }^{26}$ Essa concepção identifica-se, de certa forma, com aquela exposta por Conradi e é presente também na "Escola histórica do direito". ${ }^{27}$ A importância atribuída à

25 "Seit der Begriff des Internationalrechts sich über den Kreis des foedus hinaus erweitert hatte, was namentlich sich zeigt in dem Abkommen jener das Foedus vertretenden Waffenstillstände und der Anwendung des Fetialeninstituts gegenüber jeder Nation, ist die Unterscheidung zwischen der Kriegserklärung unter Brechung eines Vertrags und der Kriegserklärung schlechthin eigentlich gegenstandslos, da wohl kaum späterhin eine Kriegserkärung anders vorgekommen ist als unter Cassirung eines älteren internationalen Vertrags". Cf. Ibid., p. 590, nt. 2: “den nicht mit Rom in Vertrag stehenden Ausländern gegenüber bedarf es nicht der Fetialen”. Como constata Catalano (1965, p. 52 e 58) em Linee del sistema sovrannazionale romano, aqui é superado o âmbito do foedus, mas não aquele do "Vertrag". As afirmações de Mommsen e, ainda mais, aquelas do Frezza, são conexas à pretensa "naturalidade" do nomem Latinum.

${ }^{26}$ A "Escola histórica" distingue-se de Conradi, porém, pela interpretação universalística do ius fetiale, usando categorias modernas. Sobre a obra de Conradi e a sua concepção do ius fetiale, ver Ilari (1981, p.180).

27 A "Escola histórica" busca superar os limites do direito positivo, realizando para tanto uma história do direito romano. Todo esse trabalho que é fundamental para historiar o direito e combater as teorias abstratas encontra seus limites, porém, na "praticidade" e na dogmática, por buscar uma ordem sistemática única, assim como na influência do positivismo. Contrapondo-se ao jusnaturalismo, a escola histórica do direito (ORESTANO, 1963, p. 235) entende que "come il mondo físico sarebbe retto dalla legge della causalità, così il mondo morale, sociale e giuridico sarebbe retto dalla legge di finalità, sicchè il fine sarebbe il vero creatore del diritto". Essa se dedicou ao estudo do direito em cada povo, enquanto expressão do "Volksgeist", não dando atenção às pesquisas em relação às normas que, "[...] in quanto obbligatorie per popoli diversi, superavano tali particolarità" 
religião e a presença desta nas demais expressões culturais são em muito frutos do pensamento de Fustel de Coulanges.

As diferentes linhas apresentadas por essa corrente podem ser reunidas em duas grandes tendências. A primeira delineia o ius fetiale como um direito sacro ou religioso e, para alguns autores, até mesmo com características mágicas, comparando-o como um "direito público externo". A segunda valoriza o ius fetiale enquanto conjunto de institutos jurídicos ligados à realidade religiosa, ${ }^{28}$ comparando-o em linhas gerais com o "direito internacional". ${ }^{29}$

Ambas as linhas ressentem-se da influência da "Escola histórica do direito", que através de Savigny sustenta a origem do direito internacional na comunhão de sentimentos jurídicos, presente na afinidade de estirpes e principalmente em uma religião comum. Nesse quadro, nasce, segundo Savigny, o direito internacional entre os países cristãos da Europa, baseando-se em uma estrutura presente no direito romano através do "jus feciale".

O "jus feciale" é considerado, então, como um direito positivo, mas com uma formação jurídica incompleta, por duas razões: pelo seu conteúdo indeterminado e pela falta da base real que o direito encontra na autoridade do "Estado", em especial judiciária (SAVIGNY, 1840, p. 33). ${ }^{30}$

(CATALANO, 1990, p. 14). Conforme o autor, ver Spiegel (1939, p. 216); Bierzanek (1960, p. 122).

${ }^{28}$ Nesse sentido, Bouché-Leclercq (1871, p. 106) afirmava o caráter jurídico recoberto pelo aspecto religioso do direito fecial, afirmando que seus sacerdotes colocavam o direito das gentes sob a proteção dos deuses. $\mathrm{O}$ autor francês afirma os feciais como um colégio sacerdotal que se ocupava das relações com o externo, instituindo os princípios do direito internacional. Ao tratar da relação entre ius fetiale e ius gentium, esse seria prevalentemente um direito internacional público abrangido inteiramente pelos rituais do ius fetiale (BOUCHÉ-LECLERQ, 1886, p. 343, 541).

${ }^{29}$ Sobre o debate entre a concepção jurídica e aquela religiosa do ius fetiale, com reflexo na sua definição como "diritto pubblico esterno" ou "diritto internazionale", ver Catalano (1965, p. 31; 1990, p. 32): "Tuttavia la questione si trascina nella dottrina più recente, determinando, fra coloro che tendono a considerare quelle norme come di carattere non "veramente" giuridico, una definizione di esse come "diritto pubblico esterno".

30 "Indessen kann auch unter verschiedenen Völkern eine ähnliche Gemeinschaft des Rechtsbewußtseins entstehen, wie sie in Einem Volk das positive Recht erzeugt. Die 
O papel do "Estado" é ainda mais valorizado com Jhering, ${ }^{31}$ atribuindo-lhe um papel fundamental, enquanto fruto de uma estrutura cultural pré-existente e anterior à própria religião, que se torna um instrumento daquele. ${ }^{32} \mathrm{O}$ ius fetiale apresenta-se então na sua estrutura e juridicidade como permeado pela religião.

\subsection{O fundamento jurídico e o formalismo religioso do ius fetiale: a concepção como "direito internacional”}

Revon (1891, p. 31) e Weiss (1969, p. 1095) afirmam a religião como o acento de toda a sociedade, em sua cultura e conseqüentemente direito, refletindo-se também em relação ao externo, assim a religião

Grundlage dieser geistigen Gemeinschaft wird theils in einer Stammesverwandtschaft bestehen, theils und vorzüglich in gemeinsamen religiösen Überzeugungen. Daraufgründet sich das Völkerrecht, welches namentlich unter den christlich=Europäischen Staaten besteht, aber auch den alten Völkern nicht fremd war, wie es z.B. bei den Römern als jus feciale vorkommt. Auch dieses dürfen wir als positives Recht betrachten, jedoch aus zwei Gründen nur als eine unvollendete Rechtsbildung: erstlich wegen der Unvollständigkeit eines irgend sicheren Inhalts, und zweitens, weil ihm diejenige reale Grundlage fehlt, die dem Recht der einzelnen Glieder desselben Volks in der Staatsgewalt, und namentlich in dem Richteramt, gegeben ist".

31 Jhering (1907, p. 211) critica fortemente o positivismo jurídico e contextualiza o uso de determinados conceitos abstratos. Sobre a influência do positivismo sobre a historiografia do século XIX, ver Ilari (1981, p.155).

32 O autor (JHERING, 1907, p. 99) segue a tese da hostilidade natural: "Dass das Chaos, jener Zustand des indiveduellen Treibens und der Willkür den Anfang, das Völkerrecht aber den Beschluss macht ist durchaus in der Ordnung". A Antiguidade romana conhecia três autoridades eclesiásticas: os pontífices, os augures e os feciais. É possível que as funções desses fossem originalmente consultivas, mas depois tenham adquirido a autoridade de uma sentença judiciária. Os romanos respeitavam o direito e se reconheciam como sempre ligados aos seus princípios também nas relações internacionais; aplicando a si com toda a severidade o que ele fazia valer aos outros povos (p. 326). O autor analisa principalmente o ritual de indictio belli; o aspecto pacífico do ius fetiale é abordado apenas através da sagmina, como símbolo da inviolabilidade dos embaixadores romanos (JHERING, 1907, p. 564, II/2): "Der Speer ist das Symbol des Rampfes; er verkündet dem Feinde, wenn er über dessen Gränze geworfen wird, den Krieg, daheim aber gilt er als Zeichen des Eigenthums, denn der ältesten Rechtssymbolik gilt nicht die Arbeit, sondern die Erbeutung vom Feinde als die eigentliche Wurzel des Eigenthums". No vol. II/2, p. 566, o autor trata ainda sumariamente da sagmina: "das heilige Kraut (sagmina) in den Händen der Gesandten die Unantastbarkeit". 
combate ao lado dos povos, garantindo a justiça as suas causas. A sua intervenção legitima o recurso às armas e assegura aos tratados de paz ou aliança a inviolabilidade e a duração necessária (WEISS, 1969, p. 1095). Para Revon (1891, p. 42), os feciais criam uma vaga noção de "direito internacional público" e a condensam em formas solenes. Para Weiss (1880, p. 443), o colégio dos feciais faz parte do contexto das relações externas de Roma mantendo a lealdade nas "relações internacionais". Os feciais eram "magistrados" revestidos por um caráter religioso e encarregados de representar o povo romano em "atos internacionais".

Mesmo afirmando que as funções dos feciais eram de cunho religioso, político e judiciário, como quase todas as funções públicas romanas, o autor privilegia o caráter político-jurídico das mesmas, atribuindo à religião o papel de consagrá-las (WEIS, 1969, p. 1096). ${ }^{33} \mathrm{Sob}$ a República, porém, o colégio teria perdido prestígio e durante o período imperial esse participava das "relações internacionais" apenas como a memória de uma antiga tradição.

Baviera, (1898, p. 12), ${ }^{34}$ seguindo os passos de Vico (1709, p. 74) ${ }^{35}$ atribui aos institutos do ius fetiale uma natureza jurídica, sendo secundariamente ligado à esfera religiosa (BAVIERA, 1898, p. 34). ${ }^{36}$ Nesse sentido, os institutos do ius fetiale têm um fundamento

33 "Toute fois leur mission était plutôt politique que sacerdotale; ils étaient des magistrats, des juges du droit public plutôt que des pontifes; avant tout ils étaient chargés de veiller au respect des traités et à l'observation des règles du droit international, et ce n'est que par voie de conséquence qu'ils devaient accomplir les pratiques religieuses que la superstition romaine y avait attachées".

${ }^{34}$ I feziali e il diritto feziale. A obra tem um caráter principalmente de re-epílogo do material produzido precedentemente, mas mesmo assim o autor cria uma forma bastante clara de visão do direito fecial e de suas instituições. Os feciais apresentam-se então como magistrados e sacerdotes que representavam o povo romano.

35 "Igitur cum jus triplex, sacrum publicum, privatumque; e in sacro jus augurium, in publico foeciale, in privato autem actionum fórmulae continerentur."

36 "Gli Dei non c'entrano che alla lontana, poichè non crederò mai a quanto dice il Fusinato che avesse lo scopo di rendersi benigni e propizii gli Dei per il felice esito della guerra, buttandone addosso la colpa ai nemici che, colla loro giustizia, avevano negato la soddisfazione". Nessa corrente de desvalorização do elemento religioso está Phillipson (1911, p. 69, 96), na obra The internacional Law and Custom of ancient Greece and 
“exclusivamente jurídico", através dos quais é evidenciado o seu caráter pacífico (BAVIERA, 1898, p. 18). ${ }^{37}$

Ademais, o ius fetiale denota uma forte relação com o ius gentium, sendo colocado no mesmo plano histórico e "constituía um verdadeiro direito internacional público" (BAVIERA, 1898, p. 67): ${ }^{38}$ o ius fetiale enquanto complexo de regras, ritos e fórmulas usadas pelos feciais nas suas atividades; apresentava-se como uma parte do ius belli ac pacis Romanorum, complexo de princípios que presentes em outros povos, e aplicados mutuamente faziam parte também do ius gentium. ${ }^{39}$

Rome; e de certa forma também Paradisi (1944, p. 52,60) com a obra Il problema storico del diritto Internazionale e em Cívitas máxima (1974, p. 170, 187) onde evidencia a importância da religião em relação à origem do ius fetiale, desvalorizando-a no processo de laicização sofrido por esse ius. Apoiando-se na teoria de Bonfante, o autor afirma a origem do "direito internacional" em um "direito público externo", fruto das relações intergentilícias, tendo-se formado pouco a pouco diante da ausência de um direito comum das gentes. Ao evidenciar a origem consuetudinária do "direito internacional" antigo e o seu desenvolvimento em um caráter convencional com o fragilizar-se das relações étnicas, ocorre a negação de um possível caráter universalista do mesmo (PARADISE, 1944, p. 54, 187; 1940, p. 9). Ver também Ferrari, (1957, p. 254). O autor define os feciais como "magistrati-sacerdoti" aos quais evidencia uma atividade formal-religiosa, assim como o exame da equidade do caso concreto. "Al collegio dei "fetiales" spettava di compiere con efficacia vincolante, un esame preliminare sulla regolarità formale e sull'opportunità religiosa dell'atto di diritto internazionale che altro magistrato avrebbe dovuto compiere o addirittura di deliberare l'atto stesso".

37 "La funzione dei Feziali nelle relazioni di pace, esplicantisi precipuamente nella conclusione dei foedera, è di carattere religioso formalmente però, poichè in sostanza, come meglio si vedrà appresso, ha uno scopo nettamente giuridico." O autor (BAVIERA, 1898 , p. 24) contrapõe-se à hipótese criada por Fusinato de que as fórmulas de juramento presentes em Lívio e Polibio sejam partes de uma única fórmula e entende que o juramento em Roma teve uma função pretamente jurídica: “[...] era un mezzo per rendere giuridica una obbligazione spprovista di sanzione, quelle ciò̀ che non potevano assumersi colla forma del nexum".

38 Como denota Ilari (1981, p. 159), o posicionamento de Baviera demonstra-se como uma reação à validade universal da definição de direito internacional da escola positivista.

39 Sobre iura communia e direito internacional em Baviera ver Il diritto internazionale, p. $144 ; 149$. 


\subsection{O ius fetiale como direito religioso e a sua concepção como “direito público externo"}

A linha que evidencia o aspecto religioso, em relação àquele jurídico, é reforçada pela influência, mesmo que moderada, do positivismo tendo como conseqüência a diminuição da importância jurídica do ius fetiale. Nesse sentido, Osenbruggen (1836, p. 19) ${ }^{40}$ afirma o ius fetiale como parte de um direito sacro que cabe à religião pública; e Egger (1866, p. 184$)^{41}$ o define como um direito religioso, limitando a sua atuação à esfera religiosa. A compreensão do ius fetiale como um direito religioso não impede, porém, parte da doutrina de atribuir aquele alguns elementos mágicos.

Fusinato $(1884 \text {, p. } 21)^{42}$ com base em alguns aspectos das afirmações de Fustel de Coulanges (1883, p. 196), Jhering (p. 272, 273 e Beaufort (1767, p. 284), sustenta a forte influência religiosa sobre os institutos do ius fetiale. ${ }^{43} \mathrm{O}$ caráter e objetivo jurídico dos atos externos de Roma

40 "Sensu angustiori Jus Fetiale est pars juris sacri Romanorum et spectat religionem publicam. Ut totius juris sacri Fetialis sita erat in formulis, ritibus et ceremoniis, in quibus observandis populum Rom. Religiosissimum fuisse constat". O autor trata também da hipótese do ius fetiale como parte da lei das XII tábuas, como afirmado em Serv. 7,675 "Hi Fescenninas acies Aequosque Faliscos" aequos autem, dicit, i.e. justos, quia populus Rom. Missis Decemviris ab ipsis jura Fetialia et nonnulla supplementa XII tabularum accepit, quas habuerunt ab Atheniensibus", concluindo (p. 20 s.) como infundada a hipótese em base à obra de Dirksen (1824, p. 639).

41 No mesmo sentido: “On sait la superstition des Romains pour les anciennes formules de leur droit, surtout de leur religieux. Ne trouvons-nous pas, sous Claude, un citoyen nommé pater patratus, sur l'avis des oracles sibyllins, pour conclure un traité entre Rome et ce qui restait du peuple laurentin?". O autor tende a demonstrar, porém, uma certa ligação entre o "direito internacional" grego e aquele romano.

42 "I feziali costituivano in Roma un istituto giuridico e sacerdotale»; "Nè all'influenza della religione poteva mai rimanere estraneo il diritto, il quale nelle origini sue, sorto in uno Stato le cui funzioni sono concepite in maniera tutta negativa, doveva ricoverarsi per necessità sotto l'efficace protezione degli dei."

43 Seguindo essas ideias, Serafini (1896, p. 430) afirma os foedera como uma consagração do ato jurídico, uma ligação religiosa realizada após o tratado, e o conceito de guerra justa apresenta-se como estritamente religioso. "Lo ius feciale apparisce quindi più che altro un diritto formale di carattere religioso. Da questo si é voluto dedurre che Roma non abbia affatto conosciuto il diritto internazionale". A fórmula do foedus está presente de 
são fortemente revestidos pela religião e pelas suas formalidades, não constituindo uma relação jurídica no rigoroso significado (FUSINATO, 1884 , p. 12). ${ }^{44}$

O caráter jurídico da atividade relativa ao ius fetiale é visto como um "direito público externo", que regula as relações de Roma com outros povos. ${ }^{45}$ O juramento apresenta-se, então, como uma obrigação jurídica e religiosa de manter os empenhos assumidos entre dois "Estados" e de superar o originário estado de guerra entre os povos (FUSINATO, 1884, p. 78). ${ }^{46}$

O ius fetiale não se apresentava como um "direito internacional" e não é identificável com o sentido moderno de ius gentium, enquanto acordo voluntário de diferentes "Estados" (p. 14, p. 18); ${ }^{47}$ mas apresenta

forma fragmentada em Tito Lívio 1,24 e Políbio 3,25 e provavelmente era recitada pelo pater patratus e pelo general romano. Na mesma linha, de Ruggiero (1906, p. 66): Ma, poichè un semplice trattato conchiuso mediante la sponsio non aveva forza obbligatoria pei contraenti e quindi non offriva un modo legale per l'inadempimento dei patti, così per ottenere appunto questo scopo e rendere irrevocabile il trattato, si ricorreva al mezzo del giuramento, che è la parte caratteristica del foedus".

44 "Or è certo che gli usi romani, che possiamo dire di diritto internazionale, non si elevano regolarmente, come già accenato, a questa perfezione di diritto formale; [...] così che possiam ritrovare una relazione politica, religiosa, morale, non una relazione giuridica nel rigoroso significato." No mesmo sentido, ver p. 21. O formalismo religioso afirmado por Fusinato tem presente o trabalho de Stuss (1757, p. 52).

45 Referindo-se ao ius fetiale como direito público externo, Fusinato, (1884, p. 5, 18): “Il diritto internazionale primitivo di Roma non fu nè poteva essere un aüsseres Staatenrecht, come crede il Voigt, bensì fu un aüsseres Staatsrecht, governo, con la religione, e di cui le gentes costituivano non già il soggetto giuridico, ma l'oggetto, sul quale di fatto quel diritto veniva esercitato»; comparando-o ao direito internacional (p. 11). Ainda nessa mesma linha de identificação do ius fetiale como um direito público externo, ver Cimma (2000).

46 [...] "I foedera conchiusi secondo il diritto feziale hanno la stessa efficacia, che è quella d'obbligare religiosamente e giuridicamente $i$ due Stati al mantenimento delle promesse giurate". Na p. 84: "Era questo giuramento quello che perfezionava il rito, $e$ che dando all'alleanza il vero carattere religioso e giuridico creava veramente l'obbligo sacro di fronte agli dei e di fronte alla legge giuridica di mantenere con puro e pio animo i patti conchiusi".

47 Fusinato é consciente do diferente plano histórico entre ius fetiale e ius gentium. Esse último, principalmente através de Cícero, liga-se ao ius naturale que o autor trata superficialmente. 
um caráter universal assimilável ao ius belli et pacis (p. 13). ${ }^{48}$ Todos os "Estados" com os quais Roma teve contato, tinham então o seu próprio "direito público externo", nos quais se podia individuar um grupo de princípios comuns. Esse grupo de princípios era denominado ius gentium e na sua maior parte era relativo a conceitos religiosos comuns, ou a bárbaros direitos que toda a antiguidade acordava in hostes e in res hostium (FUSINATO, 1884, p. 19). ${ }^{49}$

A relação entre direito e religião torna-se mais intrínseca com Chauveau $^{50}$ que evidencia a existência do jurídico dentro do religioso. Nesse sentido, não se deve repudiar o caráter jurídico presente na vontade dos deuses, visto que o fas, mesmo sendo um direito teocrático é direito. $\mathrm{A}$ interpretação proposta pelo autor remonta às origens do ius fetiale e entende que esse, pela sua antiguidade, pode pertencer à parte do ius sacrum recebido pelos romanos, através dos demais povos habitantes da Itália. A identificação encontrada entre o ius fetiale e os procedimentos civis está numa origem comum.

A existência da relação jurídica através dos foedera implica a realização do juramento, e o eleva à altura de um contrato, pelo qual se

48 "Certo è, ripeto, che quello che a me sembra di poter asserire con sicurezza di Roma è che essa giunse bensì a porre a se stessa un certo numero di regole internazionali, $e$ a concepirle como un complesso che essa dinotava generalmente col nome di ius fetiale o con quello di ius belli et pacis; ma a quel complesso non seppe nè pote dare unità organica, nè mai lo assoggettò a ordinamento ed elaborazione scientifica".

49 "E si mostra naturale che questi precetti di diritto pubblico esterno, raggruppati insieme, venisser indicati con il nome di ius gentium, il quale si riferisce nel tempo stesso al subietto e alla sfera di applicazione del diritto medesimo".

50 Varro, pop. Rom 2,75; Cícero, off., 1,11; Tito Lívio 1,24 e 1,32; outras fontes utilizadas pelo autor: Dionísio de Halicarnasso 2,72; Polibio 3,26. CHAUVEAU, Maxime Emile. Le droit des gens dans les rapports de Rome avec les peuples de l'antiquité. In NRHDFE XV (1891), p. 443: "Même, en admettant, comme origine de toutes les prescriptions, la volonté des dieux, il ne faudrait pas encore répudier tout caractère juridique: le fas, le droit théocratique, c'est encore du droit; c'est un ensemble de préceptes applicables, soit aux rapports des hommes entre eux, soit aux rapports des peuples; en réalité la seule différence, qui le separe du droit proprement dit, du jus, ce n'est pas son caractére, sa notion essentielle, mais seulement son origine. Cette doublé conception, à la fois religieuse et juridique, se retrouve dans tous les actes de la vie internationale, aussi bien que dans les institutions qui y président". 
empenha em observar com boa fé as cláusulas do pacto lido pelo pater patratus (CHAVEAU, 1891, p. 414) ${ }^{51}$ O ius fetiale apresenta então a existência do princípio jurídico e de um certo caráter do sagrado (CHAUVEAU, 1891, p. 415). ${ }^{52}$ Refazendo-se a Fustel de Coulanges e Fusinato, o autor afirma que não se pode descartar a influência da religião nos atos das relações exteriores dos povos da Antiguidade (CHAUVEAU, 1891, p. 442). ${ }^{53}$ No direito das gentes, o caráter religioso não foi superado e mantém a coexistência dos preceitos teocráticos e das regras estabelecidas pelos homens (CHAUVEAU, 1891, p. 442). ${ }^{54}$ Nesse sentido, a noção de bona fides, fundamento das relações jurídicas entre os povos, e conseqüentemente do direito das gentes dominava mesmo após longos séculos dentro de um direito privado, universal, aplicado a todos

51 "Voilà donc un serment, joint à une convention antérieure, à l'effet de lui donner une existence juridique; le même phénomène se presente dans le jusjurandum liberti et dans le pacte prétorien, muni de l'action de jure jurando". O foedus é constituído pela invocação solene da divindade e pela realização do sacrifício, através dos quais se coloca o tratado sob a égide dos deuses. O autor trata dos tratados internacionais colocando a sponsio e o foedus em linhas paralelas; neste sentido se faz uma comparação entre o direito público e o direito privado, aproximando a sponsio, concluída através de interrogação e resposta da stipulatio. "On y trouve l'échange de volontés entre deux parties contractantes". Para o foedus, esse seria pronunciado por muitos cidadãos, naqueles mais importantes até por vinte cidadãos. CHAUVEAU Maxime Emile. Le droit des gens, p. 412 e 419. Ele aborda também a deditio, baseando-se em Tito Lívio 8,39. Convenção apoiada sobre um sermão, revestido na forma exigida para criar uma relação de direito, gerar obrigações. A cerimônia religiosa tem um papel acessório que poderia se modificar, enquanto que as exigências das condições jurídicas restam as mesmas. As afirmações são baseadas em Tito Lívio 1,24, Dionísio de Halicarnasso 2,72 (pág. 415). Refaz-se claramente ao trabalho de Fusinato nas suas conclusões afirmando que o direito é revestido pela religião em suas diversas formas, estando na base do direito privado, público e das gentes. CHAUVEAU, Maxime Emile. Le droit des gens, pág. 442. A reparação, pela ruptura dos tratados, se expressa através da "res vindicare" ou de "condicere".

52 "Mais il n'en reste pas moins vrai d'affirmer l'existence d'un principe juridique, tout comme en certaines matières du droit privé, qui ne sont point exclusives, surtout au debut, d'un certain caractere sacré".

53 "C'est de la religion, que sont venues toutes les institutions, comme tout le droit privé des anciens".

54 "Le progrés s'est fait lentement et il a fallu plusiers siècles pour achever l'évolution, la séparation du droit civil et du droit théocratique. Cette évolution n'a jamais été complete dans le droit des gent". 
os sujeitos de um império, onde o enorme desenvolvimento suprimiu a coexistência de "Estados", ou seja, a possibilidade de "relações internacionais" (CHAVEAU, 1891, p. 445).

Heuss $\left(1933\right.$, p. 4, 12, 18), ${ }^{55}$ além de contrapor-se à tese da hostilidade natural, segue os passos de Fusinato e afirma a importância do colégio dos feciais em dirigir as "relações internacionais" durante o período mais antigo, derivando dessa atividade alguns princípios (HEUS, 1933, p. 19). ${ }^{56}$ Nesse sentido, a atividade dos feciais não é meramente formal, a guerra enquanto justa e pia é ancorada na consciência de normas supranacionais e implica uma causa justa. $\mathrm{O}$ autor afirma, nesse sentido, que os romanos consideravam existentes com outros povos algumas "relações internacionais" independentes da existência de tratados.

A atividade de direito público de obrigação e responsabilidade certamente não é inseparável dos institutos religiosos, visto que, no período conhecido, a juridicidade dos atos não é mais vinculada à atividade dos feciais, definida então como sacro-jurídica. ${ }^{57}$

55 Seguindo a tese de Heuss de contraposição à hostilidade natural, embora com uma compreensão demasiadamente superficial do ius fetiale, Dahlheim (1968, p. 173):“Eine so weitgehende moralische Konzeption ist in den rudimentären Anfängen Roms, in die das Fetialrecht zurückführt, gar nicht denkbar. Richtig ist, dass der Krieg in Rom zu einer ,Rechtsexekutio' wurde, jedoch verbürgt der hier ausgesprochene Begriff ,Recht“ keine objektive Rechtmässgkeit im moralischen Sinne, die Bindung an das ius fetiale ist vielmehr eine superstitiöse und juristische, die jedes moralische Moment umbeachtet lässt". Também contrariamente à hostilidade natural: Ziegler (1972, p. 78): “Die Bindung an das ius fetiale als "eine superstitiöse und juristische, die jedes moralische Moment unbeachtet lässt”, zu qualifizieren, wie es zulest W. Dahlheim getan hat, scheint mir nicht glücklich. Rechtsformalismus und Rechtsethik sind keineswegs notwendig Gegensätze, vor alleim nicht in frühen Rechtsordnungen".

56 "Entwickelt haben sich die betreffenden Grundsätze an dem Institut der Fetialen; von den mannigfachen Funktionen, die diesem Kollegium in früher Zeit im internationalem Verkehr zukamen, geht uns hier Aufgabe bei der Kriegsklarüng an”. O autor refere-se diretamente ao trabalho de Fusinato, e como ulterior bibliografia, a Weiss, Samter e Wissowa.

57 A tradição dos feciais, recuando cada vez mais, termina por perder a importância com a política de extensão romana sobre a Itália (HEUSS, 1933, p. 21). A transformação do ius fetiale em uma tradição não mais praticada é atribuída por Paradise ao processo de separação entre direito e religião, com a laicização do ius (PARADISI, 1944, p. 52, 
Sordi (2002, p. 3-11) aprofunda a concepção de maior antiguidade da religião em relação ao direito, evidenciando a importância dessa no que diz respeito ao conceito bellum iustum ac pium, ao denotar que a guerra não poder ser sancionada somente pelo direito humano, mas deve estar em conformidade com a lei divina (SORDI, 2002, p. 3). ${ }^{58}$ A religiosidade evidente no conceito é usada como base para a afirmação de maior antiguidade em relação ao conceito de bellum iustum (p. 4) $)^{59}$ e evidencia a sua remota antiguidade, sendo provavelmente parte da mentalidade sacral do período arcaico. O caráter purum, ao invés de iustum, atribuído à guerra parece revelar um estágio anterior ao nascimento do ius e relativa a uma época onde a mentalidade prevalente é o fas. ${ }^{60}$

\section{O universalismo do sistema jurídico-religioso romano: 0 ius fetiale como "direito supranacional"}

Catalano (1965, p. 31; 1990, p. 32; 1962, p. 129) ${ }^{61}$ re-elabora a corrente que evidencia os aspectos religioso e jurídico do ius. A compenetração entre religião e direito leva o autor à concepção do ius através de um sistema jurídico-religioso, onde não há diferenciação

60; 1974, p. 170, 187). A compreensão do ius fetiale como um direito prevalentemente religioso é presente em Wissowa (1912, p. 550) e de forma muito acentuada em Gioffredi (1955, p. 10, 28): O fas "Non si tratta dei singoli riti e dei singoli precetti del culto, che sono piuttosto expressi con ius (ius pontificium, ius fetiale, ius augurum, ius religionum), ma dei fondamentali doveri religiosi, insomma del ius sacrum complessivamente considerato".

58 "La giustizia implica non solo lo ius ma anche e sopratutto il fas".

59 O caráter religioso do conceito colega-o ao ius fetiale, que dispõe de um conceito próximo na fórmula da rerum repetitio (Tito Lívio 1,32,6) "iuste pieque".

${ }^{60}$ Com base no testemunho de Polibio, do primeiro tratado entre Roma e Cartago (509 a.C.) em que, no ritual, os romanos prestaram o sermão das pedras e juraram por seus ancestrais, a autora afirma a já existência do ius fetiale, das suas fórmulas e ritos. Polibio $3,25,7$. O sermão das pedras recorda em muito a fórmula declarada pelo pater patratus para a realização do foedus, exposta na obra de Tito Lívio 1,24,4-9 (SORDI, 2002, p. 3). Segundo Zuccotti (1998, p. 44), o tipo de juramento em que consiste o sermão das pedras é presente em vários povos, em especial na Grécia, junto aos Eliasti.

${ }_{61}$ "Ché non è dato concepire per i Romani dell'età più antica una norma di ius che non sia insieme religiosa e giuridica". 
ou sobreposição de aspectos, mas uma mesma origem e natureza, demonstrando-se como indivisíveis. Observa-se, então, que dentro do período mais remoto o que é religioso também é jurídico.

$\mathrm{O}$ autor afronta através do particularismo da realidade romana e do universalismo do seu "sistema jurídico-religioso", a problemática de aplicação de conceitos modernos; superando a categoria de "direito internacional", através da validade do ius fetiale a todos os povos, independente de relações anteriores e baseando-se principalmente na vontade política tendente a uma sociedade universal. ${ }^{62}$

A universalidade do sistema jurídico-religioso romano tornase o fundamento da "supranacionalidade" expressa através do ius fetiale, ${ }^{63}$ colocando no mesmo plano o povo romano e os demais povos (CATALANO, 1965, p. 29; 1990, p. 30) ${ }^{64}$ Essa concepção implica a aplicação do ius, como elemento virtualmente válido, independente do reconhecimento ou implícito consenso dos povos estrangeiros e da sua efetividade; afirmando assim princípios de ius fetiale na formação do iura communia (CATALANO, 1965, p. 41; 1990, p. 41). ${ }^{65}$

62 A desconstrução da influência hegeliana de "Estado", assim como do influxo evolucionista demonstram-se elementos necessários para a compreensão do ius fetiale e da sua natureza supranacional (CATALANO, 1965, p. 31; 1990, p. 32).

$63 \mathrm{O}$ autor fundamenta-se particularmente na passagem Cícero, off. 3.108. Quanto à universalidade: Júpiter apresenta-se como divindade de referência no ius fetiale pela sua posição no vértice do "ordinamento cittadino", centralidade na liga latina e divindade comum aos Itálicos (CATALANO, 1965, p. 36; 1990, p. 37). Seguindo as teorias sobre o ius fetiale propostas por Catalano, ver Gaudemet (1982, p. 286); Nicolet (1978); Humbert (1978).

64 "In questo sistema giuridico-religioso è ancor più chiaro come lo ius fetiale non facesse distinzione, quanto al compimento di atti solenni, tra popoli con cui fossero e popoli con cui non fosse vigenti trattati. Anzi, se consideriamo il rapporto fra lo ius fetiale $e$ lo ius che determina la struttura interna della città, dobbiamo, seguendo il Dumézil, dire che mentre all'interno tutto era stato fatto con la fondazione iniziale, all'esterno i feziali dovevano dare una sempre nuova 'base mistica' alla 'marcia della città': necessità dunque tanto più urgente quanto più profondo si faceva l'ignoto”.

65 "I Romani [...] osservarono che presso molti popoli vigevano norme eguali: e queste dissero iura communia. Gli iura communia in parte erano compresi nello ius fetiale, in parte no (e allora erano comunque, semplicemente, iura gentium)". p. 44: "dalla validità virtualmente universale dello ius fetiale è sorta, anche attaverso l'imposizione della 
Dumézil (2000, p. 579) ${ }^{66}$ reforça a concepção de compenetração entre direito e religião como base no universalismo romano, afirmando o fas como assento místico do ius. A raiz de fas (dhe-) identifica-se com a raiz de fetiale, mostrando a sua natureza como direito religioso, «droit religieux»», e denotando as origens do ius na religião (DUMÉZIL, 2000, p. 144). ${ }^{67}$

Essa é reafirmada no objetivo do ius fetiale de garantir para Roma a proteção dos deuses nas relações com todos os outros povos. Buscar a garantia divina implicava realizar os rituais dos feciais, que anunciavam em plano divino as decisões e atividades humanas. O papel desses sacerdotes era então de lançar os fundamentos místicos do direito fora do território (ager) romano, através dos seus rituais, dentre os quais se destaca os foedera e o procedimento da indictio belli.

A análise das fórmulas atribuídas aos feciais, bem como das fontes relativas a esses, permite a afirmação de Pugliese acerca da existência de "princípios jurídico-religiosos" nas relações entre diferentes comunidades que excluíam o absoluto arbítrio do povo romano, restringindo o seu poder (PUGLIESE, 1974, p. 19). ${ }^{68}$ Esses princípios eram vistos como

maiestas del popolo romano, la validità universale di un diritto 'laico' comune". Sobre a relação ius fetiale e ius gentium, ver Lombardi (1947, p. 96, 357). O autor afirma o universalismo do ius antes mesmo da influência do pensamento helênico e para tanto baseia-se em dois institutos do ius fetiale como a inviolabilidade dos embaixadores e "il complesso formalismo della procedura feziale nella dichiarazione di guerra. In tale procedura è per me la dimostrazione della coscienza, da parte dei romani, della esistenza di un principio inderogabile, per cui non è consentito procedere alla guerra senza prima avere tentato una composizione amichevole".

66 "Le ius fetiale, c'est-à-dire les procédures assurant à Rome la protection des dieux dans ses rapports avec les peuples étrangers" [...] "Au contraire, dès que l'action de Rome sort de son ager, il faut la 'fonder' religieusement, s'assurer non seulement du ius, mais de ce qui est sous le ius, c'est-à-dire du fas: c'est à quoi pourvoient, par la *fêti-, le fetiales".

67 "fas serait l'assise mystique, invisible, sans laquelle le ius n'est pas possible, qui soutient toutes les conduites et le relations visibles définies par lo ius".

${ }^{68} \mathrm{O}$ fundamento religioso "non deve indurre a negare la natura giuridica di tali istituti e dei relativi precetti e principi. Si tratta in verità di istituti, precetti, principi giuridicoreligiosi, riguardo ai quali la distinzione tra momento giuridico e momento religioso non è giustificata”. 
fruto da vontade dos deuses, que se apresentavam como seus custodes ( $\mathrm{p}$. 19). A derivação divina dos princípios jurídico-religiosos apresentavase como um elemento comum entre os povos, superando o ordenamento interno desses, e os submetendo à ira dos deuses. Esses se manifestavam principalmente quando ocorria a guerra entre dois povos: a guerra devia ser "justa e pia" para obter os favores dos deuses, assim, tinha que ser caracterizada como reação à violação dos princípios, havendo razões e modalidades processuais conforme as regras jurídico-religiosas vigentes nas relações entre os povos. Esses princípios estavam, porém, ligados (acima ou abaixo) aos interesses políticos ou militares presentes naquelas relações.

Sini segue a mesma corrente tratando, porém, a fides dentro do "sistema jurídico-religioso" e supranacional romano, que se expressa através do ius fetiale, enquanto regulador das relações de paz e guerra durante o período régio e republicano. ${ }^{69}$

Considerando o relato de Varro (ling. 5,86) o autor trata da concepção romana (religiosa e jurídica) de fides publica como base das "relações internacionais", até mesmo em caso de guerra. ${ }^{70}$ Aquela representa a essência da vocação pacífica e da universalidade do povo romano mesmo numa história de guerras ininterruptas. ${ }^{71}$

${ }^{69}$ Dentro desse quadro, os sacerdotes feciais apresentavam-se como teóricos do direito e da política, determinando com base no caráter pacífico da religião o procedimento para a realização das guerras legítimas através de responsa e decreta dados aos magistrados e ao senado. Sini delineia, em base à passagem, Varro ling. Lat. 5,68, como funções exclusivas dos feciais guiar a fé pública entre os povos, conceber a guerra justa, constituir os tratados de paz e fazer a rerum repetitio. A exposição de Varro privilegia a hierarquia nas relações entre magistrados e sacerdotes, distanciando-se da tripartição ciceroniana e ulpianeia de ius, que afunda as suas raízes em elaborações sacerdotais de idade precedente, ou imediatamente sucessiva, à paridade entre patrícios e plebeus (SINI, 2003a, p. 482).

${ }^{70}$ Essa concepção é presente também em Gell. 20,1,39 e 40 (SINI, 2003a, p. 492). O confronto de Varro com outras fontes literárias, particularmente com Virgílio, evidencia a convicção romana da guerra como violação da religião e do direito, sendo uma ruptura traumática da paz enquanto estado natural das relações entre os povos (p. 506).

${ }^{71}$ Essa preocupação levou Roma no seu período mais antigo a produzir um sistema de regras, tornadas invioláveis pela religião, que deveriam ser utilizadas para restabelecer a fides publica inter populos e para tornar válida a guerra justa. A realização de uma guerra justa buscava colocar os deuses do lado de Roma, assim como liberar o cidadão da 


\section{Conclusões}

A análise das normas do ius fetiale enseja a constatação de que alguns dos elementos das suas noções típicas apresentam uma aplicação que se estende no tempo, através de normas presentes nos iura communia e nos iura gentium (CATALANO, 1965, p. 41; 1990, p. 42; 1960, p. 593). ${ }^{72}$

A natureza do ius fetiale, assim como a tradição relativa a esse, evidencia uma particular relação entre o jurídico e o religioso, ambos originam-se de uma mesma essência e completam-se na realidade romana mais antiga.

As fórmulas utilizadas pelos feciais denotam o uso de conceitos jurídico-religiosos próprios e refletem relações com povos e reis permeadas pela religiosidade, pela invocação direta ou indireta aos deuses. As especificidades superam a natureza e as partes da relação para abarcar a validade além dos limites da efetividade daquele ius.

Tais fatores denotam a natureza específica do ius fetiale dentro da realidade antiga, sendo incorreto pensar a sua plena aplicação fora daquela. As incompreensões também ocorrem com a sobreposição de conceitos não presentes no contexto vivido pelos feciais às atividades e normas aplicadas por esses. A busca da doutrina por enquadrar o ius fetiale como "direito internacional" ou como "direito público externo" torna-se intrinsecamente incabível, visto a sua especificidade e não identificação com os demais conceitos. Os conceitos modernos, aos quais a doutrina tenta equiparar aquele ius, pressupõe o conceito de Estado, elemento que tem suas origens na modernidade e é inexistente na realidade antiga.

impiedade do sangue derramado. O debate sobre a guerra justa dentro do jusnaturalismo da tradição filosófica grega e romana leva à concepção de Cícero em que para a guerra era necessário, então, requisitos formais (ritos do ius fetiale) e substanciais (causas validamente determináveis diante dos deuses e dos homens). Essa justificava o império romano, que buscava impor a paz (SINI, 2003b, p. 516, 539; 2003b, p. 60).

72 Nesse sentido, é particularmente interessante ter presente, como evidencia Catalano (1960, p. 593), “l'importanza che per la formazione della tradizione ebbero i documenti sacerdotali (in particolare i libri e i commentarii)". 
A doutrina jurídico-política contemporânea tem como pressuposto de Estado os elementos soberania, nação e território. Esses elementos não se enquadram, dentro da realidade jurídico-política romana formadora da urbs. Roma pode ser entendida como composta pelo populus Romanus Quirites, como coletividade e síngulos que a compõe, e os seus Deuses. Elementos que agem dentro de aspectos temporais e espaciais. ${ }^{73}$

A determinação do ius fetiale, devido a sua especifidade, seria portanto auto-indicativa podendo ser aproximado a um conceito que reflita somente as suas características, sem a pretensão de comparação ou limitação à ulteriores categorias. Nesse sentido, as considerações apresentadas por Catalano, de delinear o ius fetiale pela sua característica de regular as relações entre os homens acima da "natio" ou da "civitas" à qual pertencem, é a escolha mais sensata. O autor evita a sobreposição de conceitos modernos à realidade antiga, preservando a especificidade dos conceitos e das realidades às quais são inerentes.

$\mathrm{O}$ direito supranacional romano liga-se à realidade moderna e contemporânea como uma diferente forma de conceber e disciplinar as relações entre os homens e os povos, repassando ao Direito internacional moderno alguns princípios graças às reflexões e adaptações de filósofos e juristas às suas diferentes realidades.

\section{Referências}

ALBERT, S. Die Theorie des ,'gerechten Krieges " und ihre praktische Bedeutung für die auswärtigen Auseinandersetzungen Roms in republikanischer Zeit. Kallmünz: Frankfurt: Althistorische Studien 10, 1980.

BAYET, J. Le rite du fecial et la cornouiller magique. In: Mefra LII. Roma, 1935.

BAVIERA, G. I feziali e il diritto feziale. In: Enciclopedia giuridica romana. Milão, 1898.

Sobre o assunto, ver Catalano (1970, p. 445, 446; 1974, p. 41). 
BARBAGALLO, C. Il problema delle origini di Roma: da Vico a noi. Milão, 1926.

BELLINI, V. Il regolamento delle relazioni internazionali nell'antico Oriente. In: Archivio giuridico, CLV. Modena, 1958.

BELLINI, V. Foedus at sponsio dans l'évolution du droit International romais. In: Revue historique de droit français et étranger, IV série, XL, 1962.

BEAUFORT, L. La république Romaine. Paris, 1767.

BIERZANEK, R. Sur les origines du droit de la guerre et de la paix. In: Revue historique de droit français et etranger XXXVIII. Paris, 1960.

BLAIVE, F. Indictio belli. Recherches sur l'origine du droit fécial romain. In: Revue internacional des droits de l'antiquité. Bruxelas, 1993.

BOUCHÉ-LECLERCQ, A. Les pontifes de l'ancienne Rome. Étude historique des institutions religieuses de Rome. Paris: A. Franck, 1871. BOUCHÉ-LECLERCQ, A. Manuel des institutions romaines. Paris: Hachette, 1886.

BRASSLOFF, S. Der römische Staat und seine internationale Beziehungen. Viena, 1928.

CALORE, A. "Per Iovem Lapidem” alle origini del giuramento - sulla presenza del 'sacro' nell'esperienza giuridica romana. Milão: Giuffrè, 2000 .

CATALANO, P. Contributi allo studio del diritto augurale. Turim: Giappichelli, 1960.

CATALANO, P. Cic. de off. 3,108 e il cosiddetto diritto internazionale. In: Synteleia Arangio Ruiz I, 1964.

CATALANO, P. Linee del sistema sovrannazionale romano. Turim: Giappichelli, 1965.

CATALANO, P. La religione romana internamente. Il punto di vista giuridico. In: Studi e materiali di Storia delle religioni. LXII, 1996.

CATALANO, P. Populus Romanus Quirites. Turim: Giappichelli, 1974. 
CATALANO, P. Diritto e Persone. Turim: Giappichelli, 1990.

CIMMA, M. R. I feziali e il diritto internazionale antico. In: Ius antiquum VI, 2000. Disponível em: http://www.dirittoestoria.it/ iusantiquum/articles/N6Cimma.htm.

CONRADI, F. C. De fecialibus et iure feciali populi romani. Lipsiae, 1734.

CHAUVEAU, M. E. Le droit des gens dans les rapports de Rome avec les peuples de l'antiquité. In: Nouvelle Revue historique de droit français et étranger $X V, 1891$.

COCCHIARA, G. Storia del folclore in Europa. Turim: Boringhieri, 1952.

CRIFÒ, G. Materiali di storiografia romanistica. Turim: Giappichelli, 1998.

DAHLHEIM, W. Struktur und Entwicklung des römischen Völkerrechts im dritten und zweiten Jahrhundert v. Chr. München: Beck, 1968.

DEL PONTE, R. La religione dei romani. Milão: Rusconi, 1992.

DE RUGGIERO, E. Fetiales. Dizionario epigrafico di antichità romane, III. Roma, 1906.

DE RUGGIERO, E. Studi sul diritto pubblico romano da Niebuhr a Mommsen. Florença: successori Le Monnier, 1875.

DE TÄUBER, Michel. L'inviolabilité des traites. In: Recueil des cours de l'Academie de droit international, 32, 2. Haia, 1930.

DE VISSCHER, F. Foedus et sponsio dans l'évolution du droit international romain. In: Revue historique de droit français et étranger, IV série, XL. Paris, 1962.

DIRKSEN, H. E. Uebersicht der bisherigen Versuche zur Kritik und Herstellung des Textes der Zwölf-Tafel-Fragmente. Leipzig, 1824.

DUMÉZIL, G. La religion romaine archaïque. Paris, 2000.

EGGER, É. Études historiques sur les traités publics. Chez les grecs et chez les romains. Paris, 1866. 
FABBRINI, F. L'impero di Augusto come ordinamento sovrannazionale. Mião, 1974.

FERRARI, G. Fetiales. In: Novissimo Digesto Italiano VII. Roma, 1957. FURLANI, S. Osservazioni sui trattati internazionali hittiti. In: Studia et Documenta Historiae et Iuris, XI, 1945.

FURLANI, S. I trattati internazionali nell'antichità (I trattati dell'epoca di El-Amarna). In: Annuario di diritto comparato e di studi legislativi, XXXI. Roma, 1956.

FUSINATO, G. Dei feziale e del diritto feziale. Contributo alla storia del diritto pubblico di Roma. In: Memorie (Accademia nazionale dei Lincei, Classe di scienze morali, storiche e filologiche), Roma, 1884.

FUSTEL DE COULANGES, N. D. La cité antique. Paris, 1883.

FRAZER, J. G. Il ramo d'oro (ed. abreviada). Roma: Newton, 1999.

FRAZER, J. G. The golden bough: the magic art and the evolution of kings. Londres: Harrap. Ordish, T. F., 1891.

GANDOLFI, G.. Spunti di diritto internazionale in Tito Livio. In: Archivio giuridico, 147. Modena, 1954.

GAUDEMET, J. Les institutions de l'antiquité. 7. ed. Paris: Montchrestien, 2000.

GENTILI, A. De iure belli. Napoli: Gravier, 1770.

GIOFFREDI, C. Diritto e processo nelle antiche forme giuridiche romane. Roma, 1955.

GIULIANO, M. Rilievi sul problema storico del diritto internazionale.

In: Studi in memoria di B. Donati. Modena 1954.

HEGEL, G. W. F. Lezioni sulla filosofia della storia III. Trad. G.

Calogero C. Fatta. Florença: Bompiani, 1963.

HEUSS, A. Die völkerrechtliche Grundlage der römischen Aussenpolitik. Leipzig: Klio Beih, 31, 1933. 
HUMBERT, M. Municipium et civitas sine suffragio. L'organisation de la conquête jusqu'à la guerre sociale. Paris/Rome: Collection de l'École française de Rome, n.36, 1978.

ILARI, V. L'interpretazione storica del diritto di guerra romano fra tradizione romanistica e jusnaturalismo. Milão: Giuffrè, 1981.

JHERING, R. von. Geist des römischen Rechts. Leipzig: Breitkopf \& Härtel, 1907.

KAN, A. H. M. J. van. Régles générales du droit de la paix: l'idée de 1'organisation internationale dans ses grandes phases. In: Recueil des cours de l'Académie de Droit International de la Haye. Haia, 1938.

KASER, M. Ius gentium. In: Studia et Documenta Historiae et Iuris LIX. Köln, Weimar, Wien, 1993.

LATTE, K. Römische religionsgeschichte. München: Beck, 1960.

LAURENT, François. Études sur l'histoire de l'humanité. Gand: L. Hebbelynck, J.-B. Merry, 1850.

LE FUR, L. Précis de droit international public. Paris, 1939.

LOMBARDI, G. Sul concetto di “ius gentium”. Roma: Istituto di Diritto Romano, 1947.

MAGDELAIN, A. Essai sur les origines de la 'sponsio'. Paris, 1943.

MAGDELAIN, A. Le ius archaïque. In: MEFRA LXXXVIII. Roma, 1986.

MARQUARDT, Joachim. Le culte, in Manuel des antiquités romaines, XIII. Trad. M Brissaud. Paris: E. Thorin, 1890.

MOMMSEN, T. Römische Staatsrecht. Leipzig: Teubner, 1887.

MOMMSEN, T. Disegno del diritto publico romano. Trad. P. Bonfante, a cura de V. Arangio-Ruiz. Milão: Giuffrè, 1943.

NICOLET, C. Rome et la conquête du monde méditerranéen. 2. ed. Paris: Collection Nouvelle Clio 8bis, 1978.

ORESTANO, R. Introduzione allo studio storico del diritto romano. Turim: Giappichelli, 1963. 
OSENBRUGGEN, E. De Jure belli et pacis Romanorum. Lipsiae, 1836. PANIZZA, D. Alberico Gentili: vicenda umana e intellettuale di un giurista italiano nell'Inghilterra elisabettiana. In: GENTILI, A. Giurista e intellettuale globale. Atti del convegno Prima Giornata Gentiliana. Milão: Giuffrè, 1988.

PARADISI, B. Studi e opinioni recenti sulla storia del diritto internazionale. In: Rivista Italiana per le Scienze Giuridiche, LIV. Roma, 1947.

PARADISI, B. Il problema storico del diritto internazionale. Florença, 1944.

PARADISI, B. Civitas maxima. Florença, 1974.

PARADISI, B. Storia del diritto internazionale nel medioevo. Milão, 1940.

PHILLIPSON, Coleman. The internacional Law and Custom of ancient Greece and Rome. Glasgow: Herald, 1911.

PUGLIESE, G. Appunti sulla "deditio" dell'accusato di illeciti internazionali. In: Rivista Italiana per le Scienza Giuridiche XVIII, 1974. PRESCENDI BASEL, F. Fetiales, in Der Neue Pauly, Enzyklopädie der Antike IV. Stuttgart: Weimar, 1998.

RAMSAY, W. Fetiales. In: Dictionary of Greek and Roman Antiquities. Londres, 1875.

REDSLOB, R. Histoire des grand principes du droit des gens. Paris: Rousseau et cia, 1923.

REVON, M. Le droit de la guerre sous la Republique romaine. Grenoble, 1891.

RÜPKE, J. Domi militiae. Die religiöse Konstruktion des Krieges in Rom. Stuttgart: Franz Steiner, 1990.

SAMTER, E. Fetialis. In: Paulys Realencyclopädie der klassischen Altertumswissenschaf. Stuttgart, 1909. 
SAVIGNY, F. C. System des heutigen römischen Rechts. Berlim: bei Deit und Comp, 1840.

SCHULZ, F. History of Roman legal science. Oxford: Oxford University, 1953.

SERAFINI, E. Il diritto pubblico romano. Pisa, 1896.

SCHEID, J. Il sacerdote. In: GIARDINA, A. L'uomo romano. RomaBari: Laterza, 2003.

SINI, F. Diritto e documenti sacerdotali romani: verso una palingenesi. In: XXV Seminario Internazionale di Studi Storici "Da Roma alla Terza Roma”. Roma, 2005.

SINI, F. Documenti sacerdotali di Roma antica. Sassari: Dessì, 1983.

SINI, F. Fetiales quod fidei publicae inter populos praeerant. Riflessioni su fides e "diritto internazionale" romano (a proposito di bellum, hostis, pax). In: Il ruolo della buona fede oggetiva nell'esperienza giuridica storica e contemporanea. Pádua, 2003a.

SINI, F. Ut iustum conciperetur bellum: "guerra giusta" e sistema giuridico-religioso romano. In: Seminari di storia e di diritto III. "Guerra giusta”? Le metamorfosi di un concetto antico. Milão, 2003 b.

SPIEGEL, H. W. Ideologiekritische Bemerkungen zur Geschichte des Völkerrechts. In: Revue internationale de la théorie du droit I, Vaduz: Topos Verlag AG,1939.

SORDI, M. Bellum iustum ac pium. In: Guerra e diritto nel mondo greco e romano. Milão: Vita e Pensiero, 2002.

STUSS, J. C. Gedanke von den Fetialen des alten Roms, mit Gesner's Vorrede. Göttingen und Leipzig, 1757.

TADDEI, A. Roma. In: Studi di diritto romano. Florença, 1887.

TÄUBLER, E. Imperium romanum. Roma: Istituto di Diritto Romano, 1964.

VICO, G. B. De nostri temporis Studiorum Ratione. Napoli, 1709.

VICO, G. B. La scienza nuova. Napoli, 1744. 
VICO, G. B. De constantia iurisprudentis. Napoli, 1721.

VOIGT, M. De fetialibus populi romani, quaestionis specimen. Lipsiae, 1852.

VOIGT, M. Das jus naturale, aequum et bonum und ius gentium der Römer. Leipzig, 1858.

VOCI, P. Diritto sacro romano in età arcaica. In: Studia et Documenta Historiae et Iuris XIX. Roma, 1953.

WEISS, A. Le droit fetial et les fétiaux sous la république romaine. Paris, 1880 .

WEISS, A. Fetiales, Jus fetiale. In: Dictionnaire des antiquites grecques et romaines. Graz, 1969.

WEGNER, A. Geschichte des Volkerrechts. Stuttgart, 1936.

WISSOWA, G. Religion und Kultus der Römer. München: C. H. Beck'sche Verlagsbuchhandlung, 1912.

ZIEGLER, K.-H. Das Völkerrecht der römischen Republik. In: Aufstieg und Niedergang der römischen Welt. Geschichte und Kultur Roms im Spiegel der neueren Forschung I.2. Berlim/ Nova York, 1972.

ZOUCHE, R. Iuris et Iudicii Fecialis, sive, Iuris Inter Gentes et Quaestionum de Eodem Explicatio. Washington, 1911.

ZUCCOTTI, F. Il giuramento in Grécia e nella Roma pagana. In:

CALORE, A. Seminari di storia e di diritto. Milão, 1998.

Recebido em: 18/01/2010

Revisado em: 28/03/2010

Aprovado em: 05/04/2010 